Z. Klin. Chem. Klin. Biochem.

12. Jg. 1974, S. $336-343$

\title{
A Study of the Mechanism of the Jaffé Reaction
}

\author{
By K. G. Blass, R. J. Thibert, and L. K. Lam
}

Department of Chemistry, University of Windsor, Windsor, Ontario, Canada N9B 3P4

(Eingegangen am 21. Dezember 1973/19. März 1974)

The red Jaffé reaction product was isolated. A yellow creatinine picrate salt and an orange compound containing two molecules of creatinine per picric acid molecule were also isolated. Spectrophotometric, pH titration, and polarographic investigation of the Jaffé reaction was undertaken. Hydantoin was shown to react similarly to creatinine, while the 5,5-dimethylhydantoin was inactive. The methylene anion of creatinine is proposed to attack the meta position of picric acid, resulting in the formation of a nitro anion. A reaction structure for the Jaffe chromogen is proposed.

Das rote Produkt der Jaffé-Reaktion sowie ein gelbes Kreatinin-Pikrat und eine orangefarbene Verbindung aus zwei Molekülen Kreatinin pro Pikrinsäure-Molekül wurden isoliert. Die Jaffé-Reaktion wurde spektrophotometrisch, durch pH-Titration und polarographisch untersucht.IHydantoin reagiert ähnlich wie Kreatinin, während 5,5-Dimethylhydantoin nicht reagierte. Das Methylen-Anion des Kreatinins könnte mit der meta-Position der Pikrinsäure unter Bildung eines Nitro-Anions reagieren. Eine Strukturformel für das Jaffé-Chromogen wird vorgeschlagen.

The reaction of creatinine with alkaline picrate, commonly known as the Jaffé reaction (1), is widely employed in clinical chemistry laboratories as a routine screening for the evaluation of kidney funtion. Creatinine clearance values have been used to measure glomerular filtration rate (2-4) and elevations in amniotic fluid creatinine have been correlated with gestational age (5-8). Elevations of serum creatinine have also been used as an early sign of rejection in kidney transplant patients (9).

The Jaffé reaction is affected by over fifty chromogenic interferences (10-14). Numerous modifications of the reaction have been proposed in the literature $(11-14)$. These modifications are usually for the purpose of minimizing the effects of interfering chromogens.

Red color formation of picric acid and 1,3,5-trinitrobenzene in the presence of sodium hydroxide has been proposed to be due to Meisenheimer complex formation $(15-18)$. Other reaction mechanisms of picric acid with acetone (19-22), as well as reactions of amine groups with nitrobenzenes (23) were also reviewed. Jaffé reaction proposals have been summarized in Table 1. A large number of possible reaction ratios between picric acid, creatinine, and sodium hydroxide have been proposed. Structures suggested to account for the formation of the red Jaffé color were varied, and researchers disagreed on the groups involved in the reaction.

Although many researchers have investigated the mechanism of the Jaffe reaction and a number of structures have been proposed, much controversy still exists as to the structure of the red Jaffé chromogen. Investigation of the mechanism of this reaction was undertaken because of the wide use and importance of the Jaffé reaction in clinical chemistry. It is hoped that solving the mechanism will aid in finding a more specific reagent for the determination of creatinine.

\section{Materials and Methods , \\ Isolation of Jaffé reaction products}

Reagent grade creatinine was purchased from Fisher Scientific Company, Don Mills, Ontario, Canada. The sodium hydroxide was "Baker Analyzed" Reagent grade from J. T. Baker Ch emical Co., Phillipsburg, N. J. Reagent picric acid crystals (under water) were purchased from Allied Chemical of Morristown, New Jersey. A Fisher-Johns Melting Point Apparatus from Fisher Scientific Company, Don Mills, Ontario, Canada, was used to determine the melting point of the red Jaffe chromogen.

The red creatinine picrate was prepared by the procedure of Anslow and King (31). Creatinine, $5 \mathrm{~g}$, was dissolved in $50 \mathrm{ml}$ of distilled water. Picric acid, $10 \mathrm{~g}$, was dissolved in $200 \mathrm{ml}$ of boiling distilled water. The picric acid solution was added to the dissolved creatinine and the solution was mixed. At this point a yellow precipitate was observed. To this viscous mixture, $50 \mathrm{ml}$ of a cold solution of sodium hydroxide were added with mixing. The yellow precipitate dissolved with the appearance of a deepred solution. The red solution was cooled in an ice bath and $50 \mathrm{ml}$ of cold concentrated hydrochloric acid were added. The red chromogen of the Jaffe reaction precipitated and was collected by filtration and dried by rotary evaporation.

The yellow precipitate of creatinine and picric acid was prepared by mixing the aforementioned creatinine and picric acid solutions. The resulting yellow precipitate was cooled, filtered, and dried using a rotary evaporator.

Preparation of the orange precipitate was similar to the red, except that $15 \mathrm{~g}$ of creatinine were dissolved. During the acidification step, the concentrated acid was added very slowly. Crystals were separated by filtration of the cold solution and dried in the rotary evaporator. 
Spectrophotometric examination of the Jaffé reaction products

A Beckman DB-GT Grating Spectrophotometer with a Beckman 10 " recorder (Beckman Instruments Inc., Toronto, Ontario) was employed in the spectrophotometric studies. Spectrophotometer cells with a $2 \mathrm{~mm}$ light path were purchased from Hellma Cells Inc., Toronto, Ontario.

A solution containing the red Jaffé color was prepared for spectrophotometric examination. Creatinine, $0.0148 \mathrm{~g}$, was dissolved in $5.0 \mathrm{ml}$ of distilled water. This solution was mixed with $25 \mathrm{ml}$ of aqueous picric acid, which was prepared by adding $0.030 \mathrm{~g}$ of picric acid to $25.0 \mathrm{ml}$ of distilled water. Thirty milliliters of $0.5 \mathrm{~mol} / 1$ sodium hydroxide were added resulting in a reddish orange colored solution. The resulting $\mathrm{pH}$ of this solution was 12.94. Spectra were recorded on a Beckman DB-GT recording spectrophotometer. The $\mathrm{pH}$ was altered by titrating with 0.50 $\mathrm{mol} / 1$ hydrochloric acid. Spectra were recorded at $\mathrm{pH}$ values of $12.94,9.52,7.2$ and 5.35. The solution was then backtitrated with $0.50 \mathrm{~mol} / 1$ sodium hydroxide. Spectra of the backtitration were recorded at $\mathrm{pH}$ values of $9.48,10.78,11.9$ and 12.0 .

Polarographic examination of the Jaffé products Nitrogen $\mathbf{9 9 . 9 9 6 \%}$ pure was purchased from Liquid Carbonic of Canada Ltd. Triple distilled mercury was obtained from Engelhard Industries of Canada Ltd.

A Sargent (Sargent-Welch Scientific Company) Model XVI Polarograph was employed for this investigation. Polarographic reduction was carried out in a ten-milliliter Heyrovsky cell. The characteristics of the capillary used were: $M=1.767 \mathrm{mg} \mathrm{s}^{-1}$; $t=4.68 \mathrm{~s} ; \mathrm{m}^{2 / 3} \mathrm{t}^{1 / 6}=1.890 \mathrm{mg}^{2 / 3} \mathrm{~s}^{-1 / 2}$. The height of the mercury column was $71.5 \mathrm{~cm}$. The cell was placed in a water bath maintained at $25 \pm 0.1^{\circ} \mathrm{C}$ with a Haake Model ED "UNITHERM" constant temperature circulator.

Polarographic examination of the yellow creatinine-picric precipitate (isolated as described above) was undertaken by placing $4.0 \mathrm{mg}$ of the yellow precipitate into a $10-\mathrm{ml}$ volumetric flask. To the flask, $2.0 \mathrm{ml}$ of a $50 \mathrm{~g} / \mathrm{l}$ aqueous solution of sodium chloride were added to act as a supporting electrolyte during the polarographic reduction of the yellow precipitate. The volumetric flask was brought to volume with deionized-distilled water and the resulting yellow solution was mixed. A volume of $5.0 \mathrm{ml}$ of this solution was placed into a Heyrovsky cell which was in a $25^{\circ} \mathrm{C}$ water bath. The cell was deaerated for a period of $20 \mathrm{~min}$ with nitrogen prior to polarography.

Polarographic analysis of the red Jaffé precipitate (isolated as described above) was undertaken by weighing out $0.0050 \mathrm{~g}$ of the red precipitate into a $10-\mathrm{ml}$ volumetric flask. A volume of $4.0 \mathrm{ml}$ of $0.5 \mathrm{~mol} / 1$ sodium hydroxide was added to the flask and the volumetric flask was then filled to volume with deionized-distilled water. The resulting solution was mixed and $5.0 \mathrm{ml}$ were transferred by pipet to a 10-ml Heyrovsky polarographic cell. The cell was placed into the $25^{\circ} \mathrm{C}$ water bath and deaerated for a period of $15 \mathrm{~min}$ with nitrogen prior to polarography.

Polarographic and spectrophotometric studies of the reaction of creatinine with $m$-dinitrobenzene

Polarographic examinations were performed using a Sargent Model XVI Polarograph with the previously described capillary. Polarography was carried out in a 10-ml Heyrovsky cell which was placed in a water bath maintained at $25 \pm 0.1^{\circ} \mathrm{C}$ by a Haake Model ED "UNITHERM" constant temperature circulator. An $8 \mathrm{~mol} / 1$ sodium hydroxide solution was prepared by adding $32.0 \mathrm{~g}$ of sodium hydroxide pellets to a 100 -ml volumetric flask which was filled to volume with distilled water. A standard solution of $m$-dinitrobenzene was prepared adding $0.500 \mathrm{~g}$ of $m$-dinitrobenzene into a $500-\mathrm{ml}$ volumetric flask which was filled to volume with absolute ethanol. A volume of $0.2 \mathrm{ml}$ of the sodium hydroxide solution was added to a $10-\mathrm{ml}$ volumetric flask. To this flask, $0.1 \mathrm{ml}$ of standard $m$-dinitrobenzene was added. The flask was then filled to volume with distilled water and mixed well. A 5-ml aliquot was pipetted into the Heyrovsky cell, which was placed into the $25^{\circ} \mathrm{C}$ water bath. A 15 -min deoxygenation was carried out using $99.996 \%$ nitrogen (Liquid Carbonic), which was passed through one wash bottle containing distilled water. Blank polarograms were determined on this solution. Solid creatinine, $0.020 \mathrm{~g}$, was added to the Heyrovsky cell. The resulting solution was mixed by dcoxygenating with nitrogen for a period of $5 \mathrm{~min}$. Polarograms were run over a 3-hour period, during which a gradual decrease was observed for the diffusion current of the two reduction waves of the $m$-dinitrobenzene. Spectrophotometric spectra of the yellow solution were run against its blank on a Beckman DB-GT recording spectrophotometer.

pH titration studies of the Jaffé reaction products and related compounds

Picric acid, $0.0300 \mathrm{~g}$, was dissolved in $60 \mathrm{ml}$ of distilled water in a $150-\mathrm{ml}$ beaker. Titration of picric acid was with $0.1016 \mathrm{~mol} / \mathrm{l}$ sodium hydroxide.

Creatinine, $0.0148 \mathrm{~g}$, was dissolved in $40 \mathrm{ml}$ of distilled water and $\mathrm{pH}$ titration was with $0.1016 \mathrm{~mol} / 1$ sodium hydroxide.

Creatinine, $0.0148 \mathrm{~g}$, was dissolved in $40 \mathrm{ml}$ of distilled water and acidified with $0.10 \mathrm{ml}$ of concentrated hydrochloric acid. $\mathrm{A} \mathrm{pH}$ titration was carried out by titration with $0.1016 \mathrm{~mol} / 1$ sodium hydroxide.

The yellow precipitate of creatinine-picric acid, $0.0448 \mathrm{~g}$, was dissolved in $40 \mathrm{ml}$ of distilled water and the resulting solution was titrated with $0.1016 \mathrm{~mol} / 1$ sodium hydroxide.

The red precipitate of creatinine-picrate, $0.0448 \mathrm{~g}$, was dissolved in $40 \mathrm{ml}$ of distilled water. A volume of $14 \mathrm{ml}$ of $0.5 \mathrm{~mol} / 1$ sodium hydroxide was added with mixing and the resulting solution was titrated with $0.1169 \mathrm{~mol} / \mathrm{l}$ hydrochloric acid.

Reactivity of alkaline picrate with hydantoin and 5,5-dimethylhydantoin

Hydantoin and 5,5-dimethylhydantoin were purchased from Sigma Chemical Company, St. Louis, Missouri.

A standard hydantoin solution was prepared by adding $0.150 \mathrm{~g}$ of hydantoin to a $10-\mathrm{ml}$ volumetric flask and diluting to volume with distilled water. A standard 5,5-dimethylhydantoin solution was prepared by adding $0.150 \mathrm{~g}$ of 5,5-dimethylhydantoin to a $10-\mathrm{ml}$ volumetric flask which was filled to volume with distilled water. A standard solution of picric acid was prepared by adding $0.3238 \mathrm{~g}$ of dry picric acid to a $50-\mathrm{ml}$ volumetric flask which was filled to volume with distilled water. A spectrophotometric blanking solution was made by adding $2.0 \mathrm{ml}$ of the picric acid standard solution to $2.0 \mathrm{ml}$ of $0.50 \mathrm{~mol} / 1$ sodium hydroxide and finally, adding $0.1 \mathrm{ml}$ of distilled water. Test solutions of hydantoin and 5,5-dimethylhydantoin were prepared by adding $0.1 \mathrm{ml}$ of the respective standard solution in place of the $0.1 \mathrm{ml}$ of the water used in the blank. Spectra of hydantoin and 5,5dimethylhydantoin were prepared using a Beckman DB-GT recording spectrophotometer.

\section{Ultraviolet spectra of creatinine}

A standard creatinine solution was prepared by adding. $0.0148 \mathrm{~g}$ of creatinine to a 200 -ml volumetric flask which was filled to volume with distilled water. The $\mathrm{pH}$ of this solution was measured and a sample of it was placed into a 2-mm quartz cell. Ultraviolet spectra were obtained versus a distilled water blank using a Beckman DB-GT recording spectrophotometer.

Standard creatinine solution, $10.0 \mathrm{ml}$, was pipetted into a $100-\mathrm{ml}$ beaker, and $10.0 \mathrm{ml}$ of $0.5 \mathrm{~mol} / 1$ sodium hydroxide solution were added. The resulting solution was mixed and the $\mathrm{pH}$ of this solution was measured. A sample of it was placed into a 2-mm quartz cell for determination of the ultraviolet spectrum. A volume of this solution, $5.0 \mathrm{ml}$, was placed in a beaker and 5.0 $\mathrm{ml}$ of $0.24 \mathrm{~mol} / 1$ hydrochloric acid was added. The resulting solution was mixed, and its $\mathrm{pH}$, as well as its ultraviolet absorption spectrum were measured.

All spectra involving solutions of creatinine at the different $\mathrm{pH}$ levels studied were run in duplicate.

\section{Results}

\section{Isolation of Jaffé reaction products}

The yellow product of creatinine-picric acid, the red product of creatinine-alkaline picrate, and the orange creatinine-alkaline picrate were isolated in crystalline form. 
The red product was examined by heating on a FisherJohns Melting Point Apparatus. The red compound started to lose its brilliant red color above $160^{\circ} \mathrm{C}$. It turned orange at about $170^{\circ} \mathrm{C}$, then yellow at about $190^{\circ} \mathrm{C}$, a very pale yellow resulted about $195^{\circ} \mathrm{C}$ with a melting point just below $210^{\circ} \mathrm{C}$.

The red product was highly insoluble in most solvents. Other solvents like acetone and isobutylamine could not be used because of further chemical reactions. When small amounts of the red precipitate were dissolved in solvents like water and nitrobenzene, a yellow color resulted. The orange product also turned yellow when dissolved in water.

\section{Spectrophotometric examination of the Jaffé reaction products}

Spectra of the red Jaffe reaction product can be seen in Figures 1 and 2. The plateau in the spectrum of the Jaffé-chromogen, betweell 470-525nm, disappeared during a dilute hydrochloric acid titration. At a $\mathrm{pH}$ of 5.35 , the wave completely disappeared. A base titration of an acidified solution results in the reappearance of the Jaffé absorption wave (Fig. 2).

Polarographic examination of the Jaffé products

Polarographic examination of the yellow precipitate of creatinine and picric acid revealed a large decrease in the first reduction wave of picric acid (Fig. 3).

Polarography of the red precipitate of the Jaffé reaction resulted in a three-step reduction wave which was almost identical to that obtained for the polarographic reduction of picric acid.

Polarographic and spectrophotometric studies of the reaction of creatinine with $m$-dinitrobenzene

After the addition of creatinine to the alkaline $m$-dinitrobenzene, a gradual decrease was observed in the

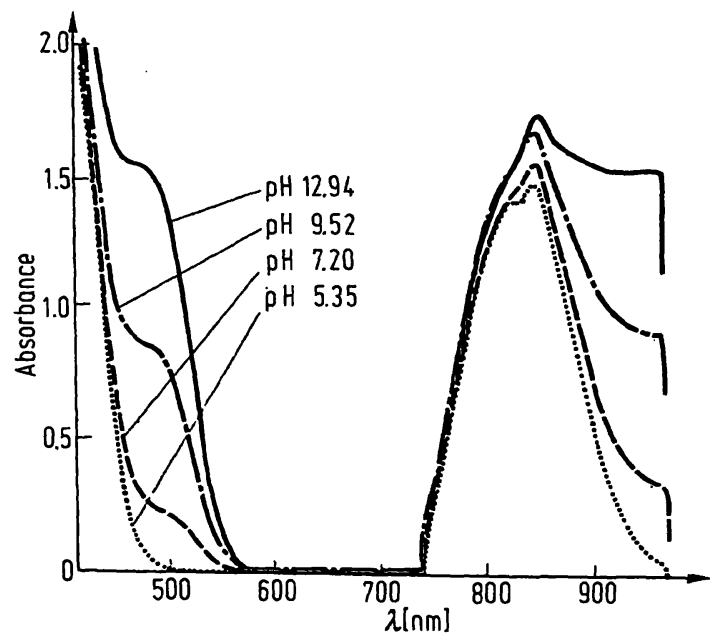

Fig. 1. Spectra of the Jaffe reaction during acid titration Spectra of the Jaffé reaction during titration with dilute hydrochloric acid are depicted. Refer to text for complete details.

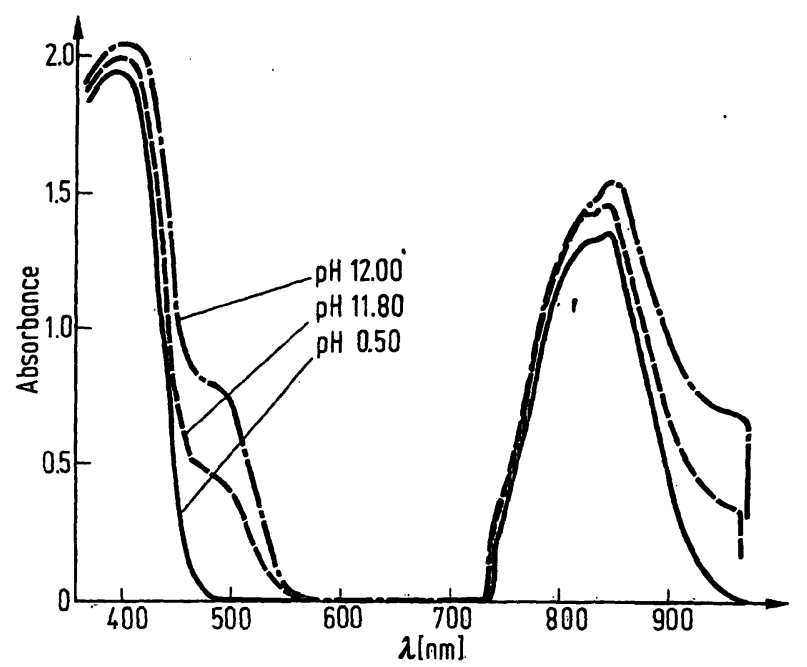

Fig. 2. Spectra ot the acidified Jaffé reaction dụring base backtitration

Spectra of the acidified Jaffé reaction during backtitration with dilute sodium hydroxide are depicted. Refer to text for complete details.

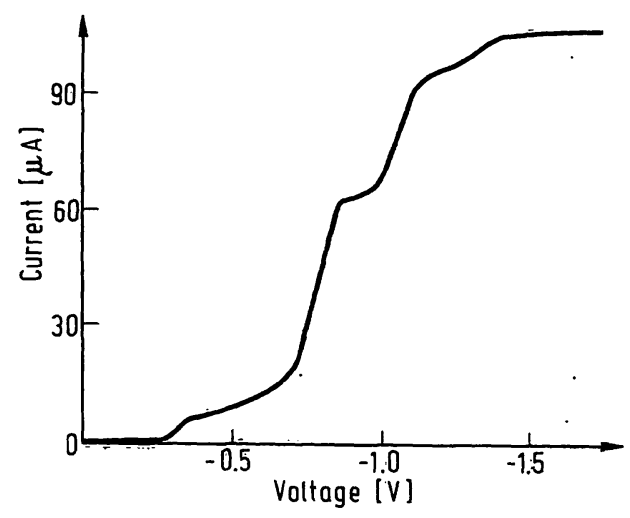

Fig. 3. Polarogram of the yellow precipitate of picric acid and creatinine

This is a typical polarogram of the yellow precipitate of picric acid and creatinine. Voltage is expressed versus mercury pool.

diffusion current of both nitro reduction waves of $m$-dinitrobenzene. The solution which remained in the 10-ml volumetric flask was used as a blank. The blank solution was clear and colorless while the solution containing the creatinine turned yellow with time. Over a 3-hour period, a gradual decrease was observed for the diffusion current of the two reduction waves of the $m$-dinitrobenzene. Spectrophotometric spectra of the yellow solution were run against its blank on a Beckmann DB-GT recording spectrophotometer.

$\mathrm{pH}$ titration studies of the Jaffé reaction products and related products

Similar $\mathrm{pH}$ titration curves for creatinine, an acidified sample of creatinine, the yellow precipitate of creatininepicric acid, and the red Jaffé reaction product were obtained. The upper portions of the titration curves of all the above were different from that of picric acid. 


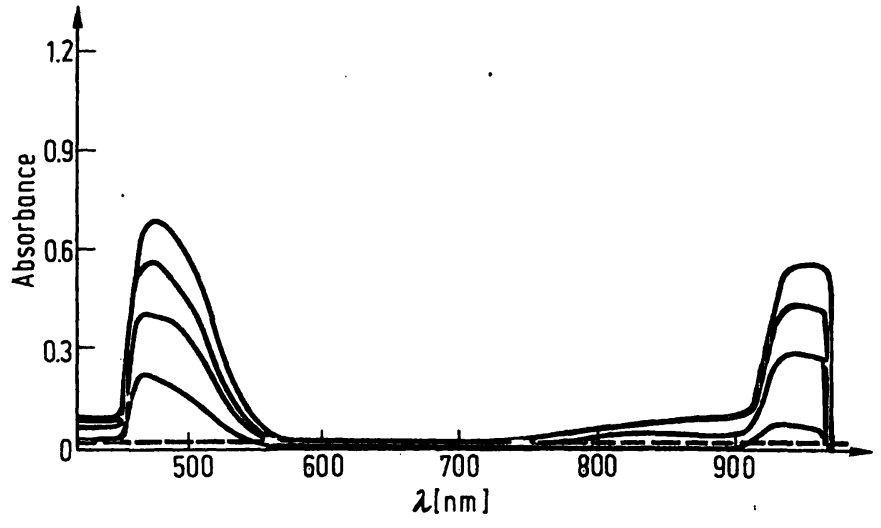

Fig. 4. Reactivity of hydantoin and 5,5-dimethylhydantoin with alkaline picrate

Hydantoin reacting with alkaline picrate is depicted.

5,5-Dimethylhydantoin in the presence of alkaline picrate is also shown. Refer to text for details.

Hydantoin

5,5-Dimethylhydantoin

Reactivity of alkaline picrate with hydantoin and 5,5-dim eth ylhydantoin

The spectra of hydantoin reacting with alkaline picrate can be seen in Figure 4. Under identical conditions, 5,5dimethylhydantoin does not react with alkaline picrate (Fig. 4): The spectra of hydantoin are very similar to the spectra of the red Jaffé chromogen (Fig. 1).

\section{Ultraviolet spectra of creatinine}

The $\mathrm{pH}$ of the standard creatinine solution was 5.9. Two absorption peaks, maxima at $235 \mathrm{~nm}$ and $200 \mathrm{~nm}$, were observed between $330 \mathrm{~nm}$ and $180 \mathrm{~nm}$.

The $\mathrm{pH}$ of the mix ture of $10.0 \mathrm{ml}$ of standard creatinine and $10.0 \mathrm{ml}$ of $0.5 \mathrm{~mol} / 1$ sodium hydroxide solution was

11.7. The maximum which was observed at $235 \mathrm{~nm}$ at $\mathrm{pH} 5.9$, became a shoulder of the $200 \mathrm{~nm}$ peak at $\mathrm{pH}$ 11.7. This latter, $200 \mathrm{~nm}$ peak, increased by $31 \%$ without taking into consideration the $2: 1$ dilution, i.e. there was a pronounced hyperchromic effect.

When $5.0 \mathrm{ml}$ of the $\mathrm{pH} 11.7$ solution was acidified with $5.0 \mathrm{ml}$ of $0.5 \mathrm{~mol} / 1$ hydrochloric acid and mixed, the resulting solution had a $\mathrm{pH}$ of 7.40 . The peaks in the ultraviolet spectrum of this solution had resolved and maxima were observed at $235 \mathrm{~nm}$ and $196 \mathrm{~nm}$, between $330 \mathrm{~nm}$ and $180 \mathrm{~nm}$.

\section{Discussion}

\section{Isolation of Jaffé reaction products}

Unlike other procedures examined, the modified Anslow and King (31) procedure for isolating the red Jaffé reaction product was very useful. The rotary evaporator which was used to remove the moisture after the filtering step, proved very. efficient. Fast alimination of moisture was necessary because of continued reaction. When properly carried out, a brilliant red precipitate was obtained. If allowed to stand moist and exposed to air, a dull dark red to brownish colored precipitate would result.

Spectrophotometric examination of the Jaffé reaction products

The superimposed spectra (Fig. 1) of the acid titration of the Jaffé chromogen at various pH levles, clearly shows the disappearance of the $470-525 \mathrm{~nm}$ wave. Similarly, the reappearance of the wave upon adding base is distincty shown in Figure 2. This difference easily lends itself to the keto and enol explanation proposed by Greenwald (32) and supported by Bollinger (33).

Polarographic examination of the Jaffé products Polarographic examination of the yellow precipitate of creatinine and picric acid revealed that the first nitro reduction wave of picric acid had disappeared. Examination of the red product, alkaline picrate-creatinine, revealed a three-wave pattern normally found for picric acid in an alkaline medium. Polarographic investigation of the formation of the red Jaffé chromogen shows the disappearance of the first reduction wave of picric acid. The initial disappearance of the nitro reduction wave and its reappearance after base treatment of the acid-precipitated compound, is an indication of a permanent bond between alkaline picrate and creatinine. The regeneration of the nitro reduction wave and reappearance of the red Jaffé color indicate that the nitro group of picric acid is not bound, as the theories of Greenwald (26) and Anslow and King (31) suggest.

Polarographic and spectrophotometric studies of the reaction of creatinine with $m$-dinitrobenzene

Both polarographic and spectrophotometric evidence indicate a reaction between creatinine and $m$-dinitrobenzene under alkaline conditions. A decrease in the diffusion current of the nitro reduction waves of $m$-dinitrobenzene was observed as the reaction time progressed. After about 3 hours, a decrease of over $50 \%$ in the diffusion current was observed for both reduction waves. The blank solution remained clear and colorless, while the test solution turned yellow.

pH Titration studies of the Jaffé reaction products and related products

The upper portions of the $\mathrm{pH}$ titration curves of creatinine, the yellow product of creatinine and picric acid, and the red Jaffé product, proved almost identical. This is an indication that the guanidino group of creatinine is not bound in the red Jaffé product, nor is it bound in the yellow product of creatinine and picric acid.

Reactivity of alkaline picrate with hydantoin and 5,5-dimethylhydantoin

Hydantoin, a molecule which is similar to creatinine, reacts with picric acid under alkaline conditions. Spectra of the hydantoin alkaline picrate reaction (Fig. 4) are 
very similar to the Jaffé reaction spectra (Fig. 1). The 5,5-dimethylhydantoin does not form a colored reaction product with alkaline pikrate. This clearly implicates involvement of the methylene group of hydantoin in the reaction with alkaline pikrate. The similarity in spectra as well as the structural similarities between hydantoin and creatinine indicate that the reactive site of creatinine involves the methylene group.

\section{Ultraviolet spectra of creatinine}

Ultraviolet spectra of creatinine at $\mathrm{pH} 5.9$ revealed two maxima which altered in intensity and wavelength with the addition of base. These changes in the ultraviolet spectra can be explained as a result of keto-enol tautomerization of the creatinine molecule. This had first been proposed by Greenwald $(26,32)$, and later supported by Bollinger (33). More recently the keto-enol tautomerization has also been suggested by Seelig (37).

\section{Summary and Conclusions}

Creatinine has been shown to react with 3,5-dinitrobenzoic acid (39-41), 1,3,5-trinitrobenzene (42), 2,4,6trinitrotoluene (42), and 2,4,6-trinitrobenzoic acid (42). The polarographic investigation reported in this paper confirms the reaction of creatinine with picric acid.

Further polarographic examination showed that creatinine can also react with 3,5-dinitrosalicylic acid (43) and with $m$-dinitrobenzene. Reaction of acetone with picric acid and 1,3,5-trinitrobenzene has been widely investigated (19-22). Kimura (19) proposed attack of the acetone anion at the meta position of picric acid. Under special conditions bicylcic reaction products of $1,3,5$ trinitrobenzene and acetone have been formed (22). These reactions, in particular, the spectrophotometric and polarographic results reported in the present study of creatinine with $m$-dinitrobenzene indicate that the attack of creatinine is at the meta position of the picric acid molecule.

Greenwald and Gross (25) were the first to isolate a compound composed of two molecules of creatinine with one of picric acid. Polarographic analysis of the 2:1 reaction product reported here, shows the disappearance of the first two nitro reduction waves of picric acid. This can be explained by attack at each of the meta positions of picric acid.

Although Meisenheimer-complex formation has been shown to occur in the presence of excess hydroxide concentration (17), this does not take place at the base concentrations widely employed in the determination of creatinine by the Jaffé procedures commonly used in clinical chemistry.

Identification of the reactive group of creatinine was done by two methods. First, titration curves of the yellow and red products of picric acid and creatinine were examined. These curves were superimposable on the titration curve of creatinine. This was an indication that the guanidino group of creatinine was not involved in the reaction with picric acid. If the guanidino group were involved in the reaction, a shift of about two $\mathrm{pH}$ units should have been observed (44). Polarographic examination shows that the nitro reduction waves of picric acid were not decreased in the presence of creatinine. Preliminary results in this laboratory indicate that guanine does not produce a color reaction with alkaline picrate and the polarographic reduction waves of picric acid were not decreased in the presence of guanine. The second piece of evidence is that hydantoin reacts with picric acid while 5,5-dimethylhydantoin does not react.

In 1928, Weise and Tropp (30) visually observed a red color formation for hydantoin and 5-methylhydantoin in alkaline picrate. They also discovered that substitution at the 1,2 or 3 positions of hydrantoin gave a positive reaction, while 5,5-ethylphenylhydantoin gave a negative reaction. They concluded that an active methylene group is required to react with the alkaline picrate, but they did not mention the type of attachment, nor did they propose a structure for the red Jaffé chromogen. Spectrophotometric results (depicted in the RESULTS section of this paper) showed very similar spectra for the hydantoin and creatinine reactions with alkaline picrate. Further spectrophotometric examination of 5,5-dimethylhydantoin proved that substitution of both methylene protons of hydantoin prevents formation of the red chromogen in the presence of alkaline picrate. Greenwald and Gross (25) found that a red color was produced with methyl substituted creatinine compounds, when the methyl groups were attached to the guanidino groups of creatinine. From the evidence presented, it is concluded that the binding site of the red Jaffé chromogen is between the meta position of the picric acid and the methylene group of creatinine. Polarographic evidence further showed that the first nitro reduction wave of picric acid was decreased in the reaction. This indicates tha the red chromogen has a nitro anion. Stability of the Jaffé product has been shown by titrating the red alkaline solution with dilute hydrochloric acid until a yellow color was obtained. The yellow solution was backtitrated with $0.5 \mathrm{~mol} / 1$ sodium hydroxide until a red color was obtained. This red solution was then examined on the polarograph. The red Jaffé color had reappeared, but the first nitro reduction wave had also reappeared. The reappearance of the first nitro reduction wave of picric acid is attributed to the loss of the negative charge which resided on the nitro group. Furthermore, this is an indication that the binding of picric acid with creatinine forms a permanent bond. Greenwald and Gross (25) found picric acid to be quantitatively inseparable from creatinine when acetic acid was added after $30 \mathrm{~min}$ of reaction time. The polarographic evidence also shows that the nitro group is not bound, as was proposed by some researchers $(26,31)$. 
On the basis of all the above evidence, the following structure is assigned to the red Jaffe chromogen:<smiles>CN(C=NC(Cl)N1C=C([N+](=O)[O-])C([N+](=O)[O-])C([N+](=O)[O-])C1)[N+](=O)[O-]</smiles>

\section{Acknowledgments}

The authors wish to thank the National Research Council of Canada for financial support of this work. The authors also wish to acknowledge the valuable technical assistance of Mr. D. H. Hill. A special note of thanks is extended to Dr. D. E. Schmidt, Department of Chemistry, University of Windsor, for his discussions during the preparation of this manuscript.

Tab. 1. Jaffé reaction proposals

\begin{tabular}{llll}
\hline Year & Researchers & Reference & Proposals for Jaffé products \\
\hline 1909 & Chapman & 24 & $\begin{array}{l}\text { The red color is due to sodium salts of picramic acid (monoamino- } \\
\text { dinitrophenol and diaminonitrophenol). } \\
\text { Reported a procedure for isolating the red product as well as noting } \\
\text { that when heated to } 139^{\circ} \text { C, it was transformed into ordinary creatini- } \\
\text { ne picrate. They concluded that only one mole of picric acid appears } \\
\text { to be required for each mole of creatinine, although the reaction was } \\
\text { not complete unless a considerable excess was present. They also no- } \\
\text { ted that if the Jaffe reaction was allowed to stand for } 30 \text { or more } \\
\text { minutes, the unchanged picric acid could no longer be recovered } \\
\text { quantitatively. } \\
\text { Believed that the red color was due to a tautomeric form of creatini- } \\
\text { ne picrate. }\end{array}$ \\
\hline $1925^{\circ}$ & 25 & Greenwald and Gross
\end{tabular}
ne picrate.

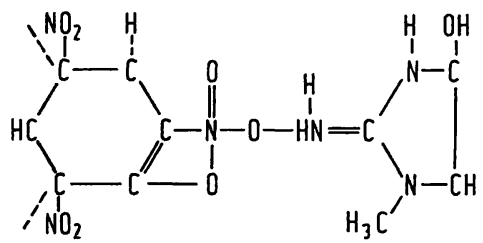

1925

1928

1928

1928
Proposed that all three nitro groups of picric acid undergo a change in the formation of the red tautomer of creatinine picrate.

Isolated an orange compound containing 2 molecules of creatinine, 1 of picric acid, 3 of sodium hydroxide and 3 of water.

Isolated the red compound which he found to be composed of 1 molecule of creatinine, 1 of picric acid, and 2 of sodium hydroxide. Examined reactivity of alkaline picrate with numerous organic chemicals. They concluded that Jaffe's reaction for creatinine is a special case of a general reaction for active methylene or methine groups. Isolated the barium salt of the Jaffé reaction product and proposed the following structure:

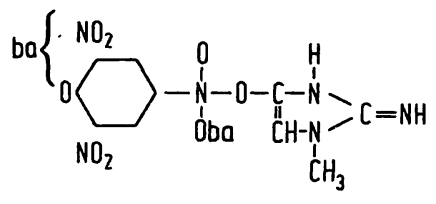

Suggested a structure for the yellow creatinine picrate:<smiles>CN1CC(=O)NC1=[V]N1OC2C3C([N+](=O)[O-])=CC([N+](=O)[O-])CC3C21</smiles>

The red tautomer was believed to result from the enolic form of creatinine. 


\begin{tabular}{|c|c|c|c|}
\hline Year & Resedrchers & Reference & Proposals for Jaffé products \\
\hline 1937 & Bollinger & $33, \cdot 34$ & $\begin{array}{l}\text { Isolated from an alcoholic medium, an orange-red crystalline com- } \\
\text { pound which consisted of one molecule of creatinine, one of picric } \\
\text { acid and two of sodium hydroxide. Acidification of the orange-red } \\
\text { compound resulted in a red crystalline compound which turned } \\
\text { orange upon heating to } 130^{\circ} \mathrm{C} \text {, yellow at } 140^{\circ} \mathrm{C} \text {, and melted at } \\
206^{\circ} \mathrm{C} \text {. He also believed enolization of creatinine to take place in an } \\
\text { alkaline medium. }\end{array}$ \\
\hline 1955 & Kimura & 19 & $\begin{array}{l}\text { Proposed a structure based on the similarity between the absorption } \\
\text { spectra of the Jaffé reaction, the Baljet reaction (picric acid with } \\
\text { the cardiac glycoside digitoxigenin), and the reaction of picric } \\
\text { acid with acetone. }\end{array}$ \\
\hline
\end{tabular}

1956

Van Pilsum et al<smiles>CN1C(=O)N(C)C([N+](=O)[O-])C1C1C2CCCC21</smiles>

olled from an alcoholic medium, an orange-red crystalline comphich consisted of one molecule of creatinine, one of picric compound resulted in a red crystalline compound which turned orange upon heating to $130^{\circ} \mathrm{C}$, yellow at $140^{\circ} \mathrm{C}$, and melted at . $206^{\circ} \mathrm{C}$. He also believed enolization of creatinine to take place in an alkaline medium spectra of the Jaffé reaction, the Baljet reaction (picric acid with acid with acetone.

Examined the Jaffé reaction at longer reaction times and higher temperatures $\left(30^{\circ}-50^{\circ} \mathrm{C}\right)$. They noted the formation of methylguanidine and a reduction product of picrate.

Reported a study of changing optical density with time at different temperatures.

Showed that spectrophotometric and chromatographic studies of the Jaffé reaction product do not compare with the frequently suggested picramic acid. He believed it to be an addition complex of one molecule of creatinine and one molecule of picric acid. Proposed the following labile structure:<smiles>[Y6]C1=CC([N+]([O-])([O-])OI2[CH]N(C)C(N)N2)C=C([N+](=O)[O-])C1Cl</smiles>

16. Abe, T. (1960), Bull. Chem. Soc. Japan 33, 41-45.

17. Abe, T. (1960), Nature, 187, 234-23.5.

18. Meisenheimer, J. (1902), Ann. Chem. 323, 205, 214, 241.

19. Kimura, M. (1955), Pharm. Bull. Japan 3, 81-83.

20. Kohashi, K., Ohkura, Y. \& Momose, T. (1970), Chem. Pharm. Bull (Tokyo) 18, 2151-2157.

21. Kohashi, K., Ohkura, Y. \& Momose, T. (1971), Chem. Pharm. Bull. (Tokyo) 19, 213-214.

22. Kabeya, T., Kohashi, K., Ohkura, Y. \& Momose, T. (1971), Chem. Pharm. Bull. 19, 645-646.

23. Crampton, M. R. \& Gold, V. (1967), J. Chem. Soc. (B), 2328.

24. Chapman, A. C. (1909), Analyst. 34, 475-483.

25. Greenwald, I. \& Gross, J. (1924), J. Biol. Chem. 59, 601612.

26. Greenwald I. (1925), J. Amer. Chem. Soc. 47, 1443-1448.

27. Greenwald, I. (1925), J. Amer. Chem. Soc. 47, 2620.

28. Greenwald, I. (1928), J. Biol. Chem. 77, 539-546.

29. Greenwald, I. (1928) J. Biol. Chem. 80, 103-106.

30. Weise, W. \& Tropp, C. (1928), Hoppe Seyler's Z. Physiol. Chem. 178, 125-138.

31. Anslow, W. K. \& King, H. (1929), J. Chem. Soc. 1210-1216.

32. Greenwald, I. (1930), J. Biol. Chem., 86, 333-343.

33. Bollinger, A. (1937), J. Proc. Roy. Soc. N. S. Wales 70, 357363.

34. Bollinger, A. (1937), J. Proc. Roy. Soc. N. S. Wales 71, 6067. 
35. Van Pilsum, J. F., Martin, R. P., Kito, E. \& Hess, J. (1956), J. Biol. Chem. 222, 225-236.

36. Archibald, R. M. (1962), J. Biol. Chem. 237, 612.

37. Seelig, H. P. (1969), this J. 7, 581-585.

38. Seelig, H. P. \& Wüst, H. (1969), Aerztl. Lab. 15, 34-39.

39. Benedict, S. R. \& Behre, J. A. (1936), J. Biol. Chem. 114, 515-532.

40. Bollinger, A. (1936), Med. J. Aust. 2, 818-821.
41. Langley, W. D. \& Evans, M., (1936), J. Biol. Chem. 115, 333-341.

42. Bollinger, A., (1936), J. Proc. Roy. Soc. N. S. Wales 70 211-217.

43. Blass, K. G. \& Thibert, R. J. (1974), Microchem. J., 19, 1-7.

44. Norman, R. O. C. (1968), Principles of Organic Synthesis, (Willmer Brothers Ltd.), Birkenhead, p. 69 Cheshire, England.

Prof. R. J. Thibert, Ph. D. University of Windsor

Windsor, Ontario N9B 3P4 Canada 